\title{
Practice marketing support, when you need it
}

There are many reasons why you might want to get started with or increase your marketing activity, for instance to:

- Help build a more loyal patient base

- Help get more patients on Denplan

- Increase sales of a product or service

- Raise the profile of your practice

- Create a strong practice identity

- Increase your patient list

- Promote one of your payment plans.

At Denplan we receive many different requests from member dentists to help with their marketing requirements. Some of these needs can be met with a simple phone call from a member of our Practice Marketing team; others require more detailed discussion in practice.

Last year we created over 1,000 pieces of practice marketing literature for our member dentists.

\section{Practice marketing visits}

Because every practice's needs are different and vary in complexity, we have dedicated practice marketing consultants (PMCs) who can visit and go through your specific marketing requirements.

Prior to the meeting, the PMC will organise a patient profile report (a complimentary service worth approximately $£ 3,000$ ) which provides essential information on your practice's existing or potential patients. This means that any marketing carried out will be tailored specifically to the audience relevant to your practice, increasing the likelihood of success.

Following a visit, and having discerned your marketing needs, the PMC will put together a detailed marketing and PR report specifically for your practice. This includes marketing activity ideas and a marketing activity plan for the year. Any literature that is required prior to a visit will also be put together by the consultant.

\section{Posters}

We often receive requests for posters to put up in waiting rooms. We can create bespoke posters for your practice or send one (or more) of our 20 general posters, which feature specific plans, oral health and general information.

\section{Websites}

With the majority of people using the net to find products and services, practice websites are now an essential part of growing your business. Weve teamed up with a company that designs websites exclusively for dental practices, where Denplan members are entitled to discounts for designing, setting up and maintaining their websites. They also provide free web health checks to ensure that existing websites are working effectively.

\section{Social media}

With so many active social media users across all age groups and across so many different media channels, it's more important than ever for practices to have a strong presence online. Denplan can help get you started and provide tips on how to manage content.

\section{Denplan Champions}

Denplan Champions are dedicated members of your team who play a pivotal role within the practice; helping to attract new patients and retain existing ones. We provide them with all the support they need, plus organise challenges and events to help them make the most of Denplan.

\section{Press releases}

Public relations (PR) is more cost effective than advertising, which is why we provide specialist support through our PR consultants. If you have a story that you think is newsworthy or would be of interest to your local community, such as a charity event, an award you have won or a practice refurbishment, we can help write the editorial for you. Because it is up to the individual publication or journalist to decide whether they use the content, we can never guarantee that articles will be accepted, but we will always do our best to get these published.

\section{Patient retention}

Marketing isn't just about telling potential patients what you offer; it's also about reminding your existing patients what services are available. Retaining your patients is far more cost effective than finding new ones. And, if your patients are loyal and satisfied they are much more likely to recommend you to others. We can help you look after your existing patients and provide you with suitable items such as fee comparison guides and referral cards to have in practice.

\section{Denplan Design}

If you fancy having a go yourself, Denplan Design is an online marketing tool for member dentists. You can create a range of marketing items such as posters, flyers, and referral cards tailored to your practice. It's easy to use and, once you have completed your design, you can send the item off to be printed. Use of Denplan Design is included as part of your Denplan membership, so you only need to pay printing costs - just don't forget to triple check spelling and grammar before sending!

If you are not yet a member of Denplan and have any questions about joining or about our services, you can book an appointment with a Denplan consultant who will be happy to provide more information.

If you are a Denplan member, you can make the most of the additional support that Denplan provide straight away. Just contact your Denplan consultant or the Practice Support team on 08003283223. 